\section{Revista Brasileira de Administração Científica}

Brazilian Journal of Scientific Administration

Abr a Jun $2021-$ v.12 - n.2
RBADM

ISSN: 2179-684X

\title{
Cerimonial universitário: análise comparativa de cerimoniais nas universidades públicas do nordeste brasileiro
}

As solenidades públicas têm na equipe de cerimonial uma maior segurança para garantia de formalidade, padronização e decoro, o que confere maior credibilidade da instituição à população e possibilita uma comunicação aproximativa com o público. Assim, o presente estudo, por meio de uma abordagem quali-quantitativa, se destina a analisar o papel do cerimonial institucional universitário, observando o caso da Universidade Federal de Alagoas - UFAL em comparação com dezessete Universidades Federais do Nordeste associadas à Associação Nacional dos Dirigentes das Instituições Federais de Ensino Superior - Andifes, levando-se em consideração a quantidade de pessoas que compõem a equipe de cerimonial e a quantidade de eventos que se encontram sob a responsabilidade dos cerimonialistas. Desse modo, identificamos como pontos de melhoria para o desempenho das atividades cerimoniais a existência de um manual de cerimonial institucional atualizado e a manutenção de uma estrutura organizada, visando colaborar na qualidade dos eventos oficiais e no atendimento às regras de conduta previstas na legislação para preservação da boa imagem da Instituição, tanto para o público interno quanto para o público externo. Por fim, como resultado, a pesquisa contribui com a valorização do cerimonial universitário, incentivo à construção de manuais para procedimentos em solenidades públicas e com a conservação de um desenho organizacional adequado às necessidades institucionais.

Palavras-chave: Eventos; Cerimonialistas; Cerimonial Público; Universidades Federais; Nordeste.

\section{University ceremonial: comparative analysis of ceremonies in public universities in Brazilian Northeast}

\begin{abstract}
Public ceremonies have greater security in the ceremonial team to guarantee formality, standardization and decorum, which gives the institution greater credibility to the population and enables an approximate communication with the public. Thus, the present study, by means of a qualitative and quantitative approach, aims to analyze the role of university institutional ceremonies, observing the case of the Universidade Federal de Alagoas - UFAL in comparison with seventeen Federal Universities in the Northeast associated with the Associação Nacional dos Dirigentes das Instituições Federais de Ensino Superior - Andifes, taking into account the number of people who make up the ceremonial team and the number of events that are under the responsibility of the ceremonialists. Thus, we identified as points of improvement for the performance of ceremonial activities the existence of an updated institutional ceremonial manual and the maintenance of an organized structure, aiming to collaborate in the quality of official events and in complying with the rules of conduct provided for in the legislation for preservation good image of the Institution, both for the internal public and for the external public. Finally, as a result, the research contributes to the enhancement of university ceremonies, encouragement to the construction of manuals for procedures in public ceremonies and the preservation of an organizational design appropriate to institutional needs.
\end{abstract}

Keywords: Events; Ceremonialists; Public Ceremonial; Federal Universities; Northeast.

Topic: Gestão Pública

Reviewed anonymously in the process of blind peer.
Received: 04/04/2021

Approved: 06/06/2021
Rafael Diego Jaires da Silva (iD)

Universidade Federal de Alagoas, Brasil

http://lattes.cnpq.br/1083624462267858

http://orcid.org/0000-0001-7294-1609

rafael.jaires@gmail.com

Nicholas Joseph Tavares da Cruz (iD

Universidade Federal de Alagoas, Brasil

http://lattes.cnpq.br/6913208549056992

http://orcid.org/0000-0003-0765-5424

nicholas.cruz@feac.ufal.br

Ibsen Mateus Bittencourt (iD

Universidade Federal de Alagoas, Brasil

http://lattes.cnpq.br/9677263203563065

http://orcid.org/0000-0002-6543-143X

ibsen.ead@gmail.com
Jovino Pinto Filho (D)

Universidade Federal de Alagoas, Brasil

http://lattes.cnpq.br/2003569347132382

http://orcid.org/0000-0001-5694-3639

jovinoadm@gmail.com
Referencing this:

SILVA, R. D. J.; CRUZ, N. J. T.; BITTENCOURT, I. M.; PINTO FILHO, J. P.. Cerimonial universitário: análise comparativa de cerimoniais nas universidades públicas do nordeste brasileiro. Revista Brasileira de Administração Científica, v.12, n.2, p.161-178, 2021. DOI: http://doi.org/10.6008/CBPC2179-684X.2021.002.0014 


\section{INTRODUÇÃO}

O cerimonial público lida com eventos institucionais e busca atender as formalidades previstas pelas normas a que se submete. Desse modo, os atos solenes exigem o cumprimento de uma sequência lógica e uma atenção especial aos protocolos e regras para as ocasiões oficiais, possibilitando a existência de um rito organizado e um ambiente de decoro pela padronização comportamental. Assim, como regulamentação, temos o decreto no 70.274/1972, que aprova as normas do cerimonial público e a ordem geral de precedência, não prescindindo demais normativos pertinentes.

Destacamos que, se uma instituição quiser ver preservada sua imagem na condução de cerimônias e eventos oficiais, de modo mais dinamizado e, ao mesmo templo, simplificado e com ordenação da sucessão das formalidades em função do tempo, é imprescindível a atuação de uma boa equipe de cerimonial para que se possa dar o devido suporte aos eventos, observando a adequação à forma, à norma e à conduta que Ihes são próprias.

Desse modo, considerando a quantidade de eventos solenes das Universidades Federais, a saber: colação de grau, posse, visitas oficiais, entrega de títulos honoríficos, medalhas, inaugurações, comemorações, aposição de retratos em galerias, aula inaugural, lançamento de pedra fundamental, abertura de exposições, seminários, congressos, lançamento de livros, premiações, assinaturas de convênios, entre outros, entendemos necessário verificar como os cerimoniais institucionais utilizam seu recurso humano para manter a padronização dos eventos e a observância às formalidades necessárias.

Tomando o exemplo da Universidade Federal de Alagoas - UFAL, além de se seguir as regras gerais de cerimonial, a instituição disciplina os procedimentos para solenidade de colação de grau por meio da resolução no 73/2018-CONSUNI/UFAL, de 05 de novembro de 2018 e possui uma equipe de três servidoras institucionalizada por meio da portaria no 69/1997-GR, de 12 de março de 1997.

Então, a partir dessas assertivas e da discussão proposta neste artigo, a questão de pesquisa tentará responder, ao final, como possibilitar o melhor desempenho do cerimonial universitário às demandas de eventos, considerando o contexto da Universidade Federal de Alagoas - UFAL, que conta com três pessoas na equipe de cerimonial institucional. $O$ estudo justifica-se pela necessidade de cumprimento das cerimônias com qualidade, observando as regras de conduta previstas na legislação para manutenção da boa imagem da Instituição, seja para o público interno quanto para o público externo.

Portanto, a pesquisa tem como objetivo analisar o papel do Cerimonial Institucional, observando o caso da UFAL em comparação às Universidades Federais do Nordeste associadas à Associação Nacional dos Dirigentes das Instituições Federais de Ensino Superior - Andifes, levando-se em consideração a quantidade de pessoas que compõem a equipe de cerimonial e a quantidade de eventos que se encontram sob a responsabilidade dos cerimonialistas. Para alcançar tal finalidade, serão identificados os eventos solenes realizados na UFAL, observadas as normas existentes sobre cerimonial aplicáveis à Universidade e propostas melhorias à condução das atividades dos cerimonialistas da instituição.

Desse modo, o presente artigo se encontra organizado em cinco partes: a primeira é a introdução, 
composta pelo tema, justificativa, objetivos e apresentação do trabalho; a segunda, na revisão teórica, apresenta objetivamente a conceituação da cerimonial, protocolo e evento, discorre sobre os principais eventos de uma universidade pública e suas normas aplicáveis e o papel dos agentes internos e externos no cerimonial institucional; a terceira trata metodologia utilizada para atingir o propósito deste estudo; a quarta refere-se a resultados e discussão mediante a análise do cerimonial institucional da UFAL e de dezessete universidades federais do Nordeste associadas à Andifes; e, por fim, a quinta refere-se à conclusão do que foi estudado, abordando de forma geral os achados da pesquisa dentro dos objetivos propostos.

\section{REVISÃO TEÓRICA}

Aqui, não temos a intenção de nos aprofundar sobre as características relacionadas a evento, cerimonial e protocolo, ou a detalhes mais específicos sobre as normas que lhes são afetas. No entanto, é salutar que haja uma mínima compreensão sobre suas definições para que haja melhores condições para distinção dos conceitos e noção dos elementos significativos ao cerimonial institucional. Como se verá a seguir, trataremos apenas o mais expressivo sobre o tema em comento, conforme revisão bibliográfica abordada, comentando o mais relevante sobre evento, cerimonial e protocolo, normas de precedência e a especificidade do cerimonial universitário e o perfil dos cerimonialistas.

\section{Evento, Cerimonial e Protocolo}

Considerando a característica inerente do ser humano de se comunicar, de se aproximar de pessoas e de se organizar na promoção de acontecimentos que envolvem a participação de um público, temos o evento, cuja definição aponta ser uma manifestação social antecipada e programada capaz de envolver e preparar pessoas em sua organização e participação, além de integrar ideias, conceitos e conhecimentos e promover produtos e serviços das organizações para alcançar objetivos em comum, suprir a necessidade de socialização e que têm uma forte característica econômica, visto que atraem um grande público e são excelentes meios de comunicação aproximativa (FREIBERGER et al., 2012; PINHEIRO, 2012).

Pelo exposto, é indubitável que os eventos estejam presentes em diversas circunstâncias sociais. Não obstante, é mister que tais atividades, em muitos casos, tenham que se revestir de formalidades, sejam essas regulamentadas por lei, normas infralegais ou tradições e costumes. Desse modo, esse conjunto de formalidades é chamado de cerimonial. Ocorre que a organização de um evento não se confunde com a atividade cerimonial, visto que esse último contempla uma necessidade maior do profissional e de sua equipe, como: bom senso, cumprimento de regras e adaptabilidade, constituindo-se, também como um meio de comunicação objetiva e dirigida (CESAR, 2016; TAKASHI, 2020).

Assim, o cerimonial ocorre dentro de um evento, dando-Ihe status. Conforme Lara (2017):

O cerimonial é o conjunto de formalidades que se devem seguir formalmente num ato solene ou cerimônia pública, com a finalidade de dar-lhes ordem e evitar constrangimento entre as partes. É a forma de realizar um ato ou cerimônia, está baseado em costumes e ou tendências. Atualmente, cerimonial é um trabalho de relações públicas, ágil, flexível, dinâmico e prático, em que se misturam elementos do passado com as exigências do mundo contemporâneo. 
Portanto, vemos que o cerimonial se relaciona à forma e possui procedimentos e diretrizes que buscam a realização do evento de maneira organizada. Para isso, envolve a ordem de precedência, a indumentária, os elementos simbólicos e os cumprimentos de ritual. Nesse sentido, o protocolo é imprescindível ao cerimonial, visto que implementa as normas fixadas. Ademais, conforme o Ministério da Educação (BRASIL, 2010), é por meio do protocolo que são conduzidos os atos oficiais com observância às regras de diplomacia e são solucionadas dúvidas sobre precedência, ou seja, quanto à ordem de quem será chamado primeiro, quem ficará ao lado de quem e do momento de pronunciamento.

\section{Precedência em Cerimônias de Caráter Público}

As regras de precedência são soluções à prática do protocolo, uma forma de dar a vez a pessoas mais importantes, haja vista o conflito diplomático sobre qual representante estatal teria a preferência aos primeiros locais em reuniões que constituía um problema desde a antiguidade. Desse modo, considerando sua relevância para o cerimonial público, temos que se refere à disposição da ordem hierárquica das autoridades de um Estado, estabelecendo sua estrutura máxima, e a colocação em que as autoridades devem estar dispostas durante a solenidade (NAANKIEL et al., 2013; DORTA, 2015; TAKASHI, 2020).

Não obstante, sabemos que não são apenas os representantes estatais que se desagradam em serem preteridos pelos demais. Naankiel et al. (2013) também expõem que é comum a qualquer homem desejar assumir o mais alto lugar de honra. Assim, pode ser entendido que as regras de precedência são imprescindíveis seja qual for a posição e o cargo dos participantes da cerimônia oficial a ser realizada.

Por isso, o decreto №. 70.274/1972, que aprovou as normas do cerimonial público e a ordem geral de precedência, passou a orientar solenidades tanto públicas quanto privadas. Desse modo, o referido decreto, em seu art. 15, conforme se vê em Brasil (1972), determina que o chefe de cerimonial, para organizar a precedência entre personalidades nacionais e estrangeiras, deve considerar "posição social, idade, cargos ou funções que ocupem ou tenham desempenhado ou a sua posição na hierarquia eclesiástica".

Também a Escola de Governo do Distrito Federal cita a necessidade de se ponderar e de se analisar circunstâncias como hierarquia, antiguidade de diplomação, cargo, idade, data de criação, ordem alfabética e bom senso. Com isso, Malerba (2010) ratifica as circunstâncias acima elencadas como princípios a serem observados para a precedência e ainda acrescenta outro fator a ser observado, a saber a questão de interesse político e comercial. Portanto, tais elementos para cumprimento das precedências são importantes para orientação do organizador e para estabelecimento de preeminências nos locais de assentos.

\section{Cerimonial Universitário}

Não obstante o decreto $\mathrm{n}$ - . 70.274/1972 ser padrão normativo, o cerimonial pode contar com algumas especificidades. Borges (2002) cita algumas classificações próprias, a saber: cerimonial público, cerimonial privado, cerimonial estrangeiro, cerimonial diplomático, cerimonial protocolar ou de chancelaria, cerimonial de corte ou político e cerimonial eclesiástico. Assim, o cerimonial universitário das universidades federais insere-se entre os cerimoniais públicos e, conforme Bettega (2005): 
[...] consiste em uma atividade administrativa que envolve planejamento, administração, coordenação e controle de ritos acadêmicos. Tendo surgido ao mesmo tempo da figura do Reitor, aproximadamente no ano 1.200 d.C., quando a esta autoridade era concedida os plenos poderes para representar a Instituição nas Solenidades de Colação de Grau.

Essas atividades administrativas das universidades são exemplificadas por um autor em 1998, como: "atos de posse do reitor, pró-reitores, chefes de departamentos, instalação de colegiados, aula magna, concessão de títulos, colação de grau, etc.". Ademais, Lara (2017) ratifica que os eventos podem envolver características das diferenças regionais e culturais. E, aqui, percebemos que as especificidades podem aparecer tanto pela diferença geográfica, quanto pela diferença das funções do órgão. Portanto, é notável a existência de normativas específicas em eventos locais, em conformidade com a cultura organizacional.

Nesse sentido,

As universidades devem seguir este Decreto em solenidades com a presença de autoridades que não sejam da universidade, mas devem, também, respeitar a Ordem de Precedência da Universidade. Poucas universidades já incorporaram, no seu cotidiano, as suas próprias regras de cerimonial, aprovadas por Conselho Universitário. Estas regras são necessárias principalmente para orientar e indicar procedimentos de cerimonial nas atividades universitárias.

Assim, conforme Pinheiro (2012), o cerimonial público nas universidades federais também deve observar a existência das próprias regras locais, de acordo com a aprovação interna pelo conselho universitário, para um adequado andamento das solenidades institucionais. Com isso, compreendemos a importância de a Universidade se atentar para seu desenho organizacional, de maneira que, conforme ensinamento de Chiavenato (2008), satisfaça suas demandas e aloque seus recursos para melhor vantagem, considerando: o ambiente, a estratégia, a tecnologia, o tamanho e ciclo de vida e as pessoas.

Por isso, Ivo et al. (2014), ao sinalizarem orientações básicas para realização de eventos em Instituições de Ensino Superior, tomando como base o contexto da Universidade Federal de Santa Maria (UFSM), mostram ser de bom alvitre que, conforme cada contexto, se forme comissões capacitadas a atividades específicas. Nesse caso, citam dez possíveis comissões: central organizadora; de infraestrutura; de informática; de recepção; de segurança e hospitalar; de relações públicas e marketing; de hospedagem e alimentação; de finanças; de transporte; e cultural. Dessa forma, tais comissões são relacionadas aos diversos setores da Universidade, conforme competência que lhes for inerente.

Ocorre que é dever das Instituições de Ensino Superior, possibilitar as adequadas condições de trabalho diante dos desafios da gestão universitária contemporânea:

A IES deve preocupar-se em oferecer e conservar as condições ideais para a realização das
atividades e obter, assim, uma ótima performance. O colaborador, ao usufruir dessas
condições, terá como retorno a realização profissional. Ao manter profissionais talentosos,
a empresa estará usufruindo de todo o investimento alocado para a captação e para o
desenvolvimento de seu capital humano, além de obter ganhos na produtividade e na
competitividade, bem como o alcance de resultados inestimáveis. Por outro lado, com a
saída de colaboradores (perda de talentos para o mercado), estará deixando de obter
retornos positivos, perdendo, por conseguinte, recursos financeiros. (COLOMBO et al.,
2011)

Assim, as universidades, ao criarem um ambiente motivador, se beneficiarão pela realização profissional de sua equipe. Ou seja, conservarão profissionais talentosos em seus quadros, o que culminará 
em produtividade e competitividade da instituição. No caso do cerimonial, uma boa equipe é imprescindível para transmitir uma boa imagem perante o público interno e externo e garantir a comunicação aproximativa.

Finalmente, outro fator importante sobre o cerimonial universitário é apresentado por Silva (2008) que, ao pesquisar sobre as defesas de monografia dos alunos do curso de Turismo da Universidade de Fortaleza, observou que a aplicação de protocolo concedeu uma imagem de maior seriedade e maior respeito ao momento, evitando interferências inapropriadas e possibilitando um sentimento de maior maturidade aos graduandos diante da responsabilidade de apresentar o trabalho de conclusão de curso.

\section{Perfil dos componentes da equipe de cerimonial}

Considerando a relevância das atividades que estão sob a responsabilidade do cerimonial, bem como as características solenes dos eventos institucionais e as suas repercussões para manutenção da boa imagem do órgão público, ficamos na expectativa que o perfil dos cerimonialistas atenda a alguns pré-requisitos essenciais às atribuições que Ihes são incumbidas.

Conforme referencial teórico (BORGES, 2002; FREIBERGER et al., 2012), os cerimonialista se destacam pela elaboração de convites, atualização de listas de autoridades, lembretes de datas importantes, organização e recepção a visitantes, compra de presentes para troca de cortesias e reservas de aeronaves, de sala VIP, de hotéis, segurança, etc. Também devem se destacar pela pontualidade, boa apresentação (roupa, gestos, tom de voz), aparência, verbalização, discrição e conhecimento de cerimonial.

Salientamos que não se deve confundir o chefe de cerimonial com o mestre de cerimônias. 0 primeiro tem a função de coordenar e planejar o cerimonial e deve agilizar as providências necessárias à sequência do cerimonial, enquanto o segundo é o que conduz os atos da solenidade, apresenta o evento e deve estar atrelado à tribuna (SILVA, 2007; MALERBA, 2010; YANES, 2014). Assim, o mestre de cerimônia, deve ter domínio amplo e conhecimento das autoridades, técnicas de oratória, conhecimentos sobre cerimoniais e regras de etiquetas, saber lidar com imprevistos, ter postura e boa aparência e o chefe de cerimonial deve dominar a legislação, conhecer os diversos tipos de cerimoniais, ser próximo da alta administração e ter habilidade para fazer roteiro e script a ser lido pelo mestre de cerimônia.

Quanto à formação acadêmica, pesquisa de Carvalho et al. (2018) aponta que equipes de cerimonial são ocupados por egressos de diferentes cursos de graduação, sendo portadores de diploma de Comunicação Social, História, Jornalismo, Pedagogia, Teologia, Secretariado Executivo, Tecnologia em Eventos e Tecnologia em Gestão de Turismo, Letras e que, em instituições públicas, a predominância é de profissionais graduados em comunicação social com habilitação em jornalismo.

Já Roque et al. (2017) destacam o secretário executivo como um profissional com competência para gerenciar eventos, apontando que a formação acadêmica fornece habilidades de planejamento, organização, liderança, polivalência e uso das normas de cerimonial, protocolo e etiqueta. Assim, em pesquisa com as prefeituras dos cinco maiores municípios do estado de Santa Catarina, Hasckel et al. (2011) constataram que todos possuem ensino superior completo em uma das áreas das habilitações de comunicação; que são experientes na área de eventos; que ocupam cargo de confiança; e que possuem cargos próximos ao prefeito. 
De toda forma, Takashi (2020) destaca que o cerimonialista deve conduzir seu trabalho com base no bom senso, boa organização e boa vontade, o que chama de três B's, mas não prescindindo o conhecimento técnico. $E$, nesse sentido, havendo carência de pessoal qualificado em seus quadros, a Administração se depara com duas possibilidades, conforme explica Borges et al. (2018), realizar concurso público ou terceirizar, sendo esse último, na visão de Chiavenato (2010) uma maneira de inovar a estrutura organizacional que possibilita agilidade e flexibilidade na organização.

\section{METODOLOGIA}

Este estudo pretende analisar o papel do Cerimonial Institucional e a sua importância na realização de eventos nas Universidades Federais. Logo, por ser dirigido à solução de problemas específicos, pela classificação de Silva et al. (2005), trata-se de pesquisa aplicada. Não obstante, a presente pesquisa, por pretender desenvolver hipóteses, aumentar a familiaridade com o fato estudado e modificar e esclarecer conceitos, também poderá ser classificada como exploratória, nos termos de Lakatos et al. (2017).

Diante disso, investigaremos a atuação dos cerimoniais institucionais de algumas universidades federais do Nordeste brasileiro na condução e organização dos eventos oficiais. Para tanto, a abordagem da pesquisa em contento pode ser considerada como quali-quantitativa, pois contará com a observação e interpretação dos pesquisadores quanto aos dados coletados e, concomitantemente, contará com análise estatística, considerando a quantidade de componentes da equipe de cerimonial e a quantidade de eventos que estão sob responsabilidade das universidades pesquisadas entre os anos 2015 e 2019.

Assim, procederemos à investigação dos principais desafios passíveis de generalização, buscando entender como uma equipe com três pessoas consegue conduzir uma grande quantidade de eventos na Instituição. Para tanto, utilizaremos como ferramenta de coleta de dados a análise de conteúdo e a observação participante. Conforme leciona Zanella (2009), a análise de conteúdo leva em conta tanto os escritos produzidos dentro quanto de fora da pesquisa, ou seja, os que decorrem de entrevistas e observações, quanto livros, jornais e documentos de organizações. Desse modo, nesta pesquisa, além dos dados coletados no referencial teórico, serão extraídas informações disponíveis nas normativas internas e externas à UFAL e nas informações institucionais fornecidas.

Assim, os dados foram coletados conforme disposições contidas no decreto no 70.274/1972, bem como nas informações disponibilizadas por meio da plataforma FalaBR ${ }^{1}$ para acesso à informação, cujas solicitações foram enviadas a dezoito universidades federais do Nordeste, tomando-se como critério de escolha aquelas que se encontram Associação Nacional dos Dirigentes das Instituições Federais de Ensino Superior - Andifes, conforme Tabela 1.

Tabela 1: Pedidos de Acesso à informação às Universidades Federais do Nordeste associadas à Andifes.

\begin{tabular}{lll}
\hline Universidade & No de Protocolo & Código de Acesso \\
\hline Universidade Federal de Alagoas - UFAL & $23546.041415 / 2020-23$ & rtsd7190 \\
Universidade Federal da Bahia - UFBA & $23546.041416 / 2020-78$ & esvd2431 \\
Universidade Federal do Ceará - UFC & $23546.041420 / 2020-36$ & ipzj3804
\end{tabular}

${ }^{1}$ https://sistema.ouvidorias.gov.br 
Universidade Federal do Cariri - UFCA

Universidade Federal de Campina Grande - UFCG

Universidade Federal Rural do Semiárido - UFERSA

Universidade Federal do Sul da Bahia - UFESBA

Universidade Federal do Maranhão - UFMA

Universidade Federal do Oeste da Bahia - UFOB

Universidade Federal da Paraíba - UFPB

Universidade Federal de Pernambuco - UFPE

Universidade Federal do Recôncavo da Bahia - UFRB

Universidade Federal do Rio Grande do Norte - UFRN

Universidade Federal Rural de Pernambuco - UFRPE

Universidade Federal de Sergipe - UFS

Universidade da Integração Internacional da Lusofonia Afro-Brasileira - UNILAB

Universidade Federal do Vale do São Francisco - UNIVASF
23546.041421/2020-81
23546.041424/2020-14
23546.041430/2020-71
$23546.041419 / 2020-10$
23546.041423/2020-70
23546.041417/2020-12
23546.047283/2020-43
23546.041426/2020-11
23546.041418/2020-67
23546.041431/2020-16
23546.041427/2020-58
23546.041432/2020-61
23546.041422/2020-25
23546.041428/2020-01
rqnc7045
pvvz6505
iyxc3769
rgim7110
wdoo8936
ooht6128
onto5996
tulv7826
wdin8691
xako9160
rnwg7045
ngfk5581
kium4614
ftys 2849

No protocolo para acesso às informações, registrou-se o pedido com o seguinte conteúdo:
a) O cerimonial institucional da Universidade é composto por quantos membros?
b) Quantos eventos foram acompanhados pelo Cerimonial em 2015?
c) Quantos eventos foram acompanhados pelo Cerimonial em 2016?
d) Quantos eventos foram acompanhados pelo Cerimonial em 2017?
e) Quantos eventos foram acompanhados pelo Cerimonial em 2018?
f) Quantos eventos foram acompanhados pelo Cerimonial em 2019?

Cumulada à análise de conteúdo supramencionada, a pesquisa também se fundamenta na observação participante que, nos dizeres de Gil (2008), se trata de uma observação ativa, real, onde o observador ocupa, até certo ponto, o papel de um membro do grupo. Assim ocorre pelo fato de um dos pesquisadores deste estudo ser servidor lotado no Gabinete da Reitoria da UFAL, unidade a qual o Cerimonial Institucional se encontra vinculado.

Quanto à amostra, conforme lições de Prando (2018), essa corresponde a qualquer parte de uma população que facilita a coleta de dados, deixando-os organizados, e seleciona elementos relevantes para a pesquisa. Salienta existir dois tipos de amostras: a probabilística, com base em elementos estatísticos, categorizada como aleatória simples, ou estratificada ou por conglomerado; e a não-probabilística, classificada por conveniência e por julgamento e por quotas.

Neste artigo, foi selecionada uma amostra não-probabilística por julgamento, correspondendo ao que os pesquisadores consideram como representativo, haja vista o conhecimento mais aprofundado que possuem sobre a população-alvo e pelo o cerimonial institucional se tratar de rotina do gabinete reitoral, o qual um dos pesquisadores se encontra lotado há mais de 07 (sete) anos como servidor. Desse modo, o estudo de caso se debruçará sobre o Cerimonial Institucional, numa análise comparativa com 17 universidades federais do Nordeste brasileiro, visto que uma das universidades não apresentou resposta.

Considerando a análise a ser realizada, para Lakatos et al. (2017), essa é realizada no nível da interpretação, da explicação e da especificação para conseguir respostas às suas perguntas, relacionando os dados obtidos com as hipóteses formuladas. Assim, seguindo-se à compreensão da interpretação dos dados, de forma ampla, entende-se da busca do significado do material apresentado, considerando os objetivos propostos, colocado de forma clara e acessível os dados obtidos na pesquisa.

Desse modo, realizamos análise quantitativa dos dados, cujo tratamento seguiu as seguintes 
operações: análise descritiva dos dados com média aritmética e desvio padrão. A normalidade das distribuições de equipe de cerimonial nas universidades foi testada usando testes de normalidade de Shapiro-Wilk, que é o mais indicado para amostras reduzidas, considerando o tamanho da amostra menor que 30 observações (Tabela 2). Em sequência, efetuamos correlações bivariadas tau de Kendall, considerando o número pequeno de amostra (FIELD, 2017), para aferir a existência de associação entre as variáveis estudadas, sendo com nível de confiança de $95 \%, \mathrm{P}<0,05$ e teste paramétrico (teste t).

Quanto ao aspecto qualitativo, os dados obtidos também se submeteram à análise interpretativa, com exposição do resumo da conclusão relevante e exposição das limitações e recomendações. Para tanto, por meio de análise documental dos dados do Gabinete Reitoral da UFAL e das informações obtidas pela Plataforma FalaBR, analisamos os principais eventos solenes, fazendo comparação entre as Universidades Federais do Nordestes associadas à Andifes com fulcro de identificar as principais dos cerimoniais institucionais e propor melhorias para o adequado desenvolvimento das atividades.

\section{RESULTADOS E DISCUSSÃO}

\section{O cerimonial universitário nas universidades do Nordeste associadas à Andifes}

A partir das informações fornecidas por meio da Plataforma Integrada de Ouvidoria e Acesso à Informação (FalaBR), obtivemos dados referentes à quantidade de pessoas que compõe a equipe de cerimonial institucional e a quantidade de eventos realizados entre 2015 e 2019 em 17 (dezesseis) Universidades Federais do Nordeste, conforme Tabela 2. O critério utilizado para a escolha dessas instituições foi o fato dessas serem federais, pertencerem ao Nordeste e de estarem associadas à Andifes.

Desse modo, primeiro observamos como as universidades do Nordeste selecionadas têm dimensionado sua equipe de cerimonial face à quantidade de eventos que se encontram responsáveis por organizar, para, após, comparar com as especificidades da UFAL.

Tabela 2: Respostas aos pedidos de Acesso à informação às Universidades Federais do Nordeste associadas à Andifes.

\begin{tabular}{|c|c|c|c|c|c|c|c|}
\hline Universidade & Sigla & $\begin{array}{l}\text { Equipe } \\
\text { Cerimonial }\end{array}$ & $\begin{array}{l}\text { Eventos } \\
2015\end{array}$ & $\begin{array}{l}\text { Eventos } \\
2016\end{array}$ & $\begin{array}{l}\text { Eventos } \\
2017\end{array}$ & $\begin{array}{l}\text { Eventos } \\
2018\end{array}$ & $\begin{array}{l}\text { Eventos } \\
2019\end{array}$ \\
\hline $\begin{array}{l}\text { Universidade da Integração Internacional da } \\
\text { Lusofonia Afro-Brasileira }\end{array}$ & $\begin{array}{l}\text { UNILA } \\
\text { B }\end{array}$ & 1 & -- & 3 & 3 & 2 & 2 \\
\hline Universidade Federal da Bahia & UFBA & 2 & 31 & 72 & 45 & 55 & 24 \\
\hline Universidade Federal da Paraíba & UFPB & 1 & 52 & 52 & 52 & 80 & 42 \\
\hline Universidade Federal de Alagoas & UFAL & 3 & 66 & 68 & 102 & 100 & 76 \\
\hline Universidade Federal de Campina Grande & UFCG & 0 & -- & -- & -- & -- & -- \\
\hline Universidade Federal de Pernambuco & UFPE & 4 & 150 & 136 & 146 & 144 & 192 \\
\hline Universidade Federal de Sergipe & UFS & 3 & 74 & 62 & 51 & 50 & 37 \\
\hline Universidade Federal do Cariri & UFCA & 3 & -- & -- & 15 & 19 & 23 \\
\hline Universidade Federal do Ceará & UFC & 3 & 110 & 110 & 155 & 151 & 156 \\
\hline Universidade Federal do Maranhão & UFMA & 8 & 134 & 24 & 12 & 30 & 38 \\
\hline Universidade Federal do Oeste da Bahia & UFOB & 1 & -- & -- & -- & -- & -- \\
\hline Universidade Federal do Recôncavo da Bahia & UFRB & 1 & 17 & 19 & 18 & 20 & 15 \\
\hline Universidade Federal do Rio Grande do Norte & UFRN & 4 & 139 & 151 & 127 & 127 & 134 \\
\hline Universidade Federal do Sul da Bahia & $\begin{array}{l}\text { UFES } \\
\text { BA }\end{array}$ & 1 & 33 & 29 & 42 & 47 & 7 \\
\hline Universidade Federal do Vale do São Francisco & $\begin{array}{l}\text { UNIV } \\
\text { ASF }\end{array}$ & 2 & 39 & 43 & 27 & 30 & 36 \\
\hline Universidade Federal Rural de Pernambuco & UFRP & 7 & 19 & 13 & 37 & 37 & 54 \\
\hline
\end{tabular}


Aqui, cabem certas considerações. Primeiramente, algumas das universidades supramencionadas nem sempre tiveram equipe de cerimonial institucionalizada. O cerimonial da UNILAB foi instituído apenas em 2016; quanto à UFCA, em fevereiro de 2017; o da UFOB, no final de janeiro de 2020; e o da UNIVASF, em maio de 2019. Não obstante, essa última universidade informou que, antes de maio de 2019, atividades de cerimonial ficavam sob responsabilidade da Coordenação de Serviços Especializados (CSE), subordinada à Pró-Reitoria de Planejamento e Desenvolvimento Institucional (PROLADI).

Outra informação relevante é que a UFCG não possui cerimonial institucional. Desse modo, na realização de seus eventos, a referida instituição esclareceu que:

Em eventos relativos a cada Unidade Acadêmica ou Centro ou setor da administração central da instituição, é formada uma comissão com servidores da própria unidade acadêmica ou centro ou do próprio setor que se encarrega da organização e realização de cada evento.

Para eventos maiores, como Colação de Grau, é formada uma comissão mista com servidores dos Centros do campus sede, Campina Grande, que cuidam da organização e realização para cada Período Letivo.

Quando se trata de colação de grau dos campi fora de sede, cada Diretor de Centro/campus institui uma comissão para cada evento.

E, para os eventos com patrocínio de agências de fomento (workshops, seminários e congressos), realizados com apoio institucional da UFCG, os organizadores do evento contratam uma empresa de cerimonial que cuida de todas as etapas de organização e realização do evento.

Isso mostra consonância com o pensamento de Chiavenato (2010) quanto às diferentes formas usadas pelos órgãos públicos de se arranjar a estrutura organizacional, visando a manutenção da agilidade e flexibilidade em seus procedimentos e também corrobora com os ensinos de Borges et al. (2018) no sentido que, em alguns casos, a Administração tende a usar a alternativa da terceirização.

É como o caso da UFSB, cuja informação fornecida foi que em "dezembro de 2018, o cerimonial foi desativado e criou-se no [sic] setor de gestão de eventos tendo como responsabilidade apenas a administração do contrato". Logo, temos que uma equipe institucionalizada, para algumas universidades, pode estar associada ao passado ou ao futuro de sua organização, a depender do contexto e do entender da gestão para melhor condução das atividades.

Salientamos, de toda forma, que a equipe de cerimonial de algumas universidades geralmente conta com o apoio de outros servidores, terceirizados, bolsistas e/ou estagiários, conforme informado por sete universidades, a saber: UFRB, UFS, UFCA, UFMA, UFRB, UFRN, UFRPE. Ademais, ressaltamos que, além dos eventos oficiais, algumas universidades relataram que realizam diversos atendimentos, auxiliam eventos de outras unidades e exercem atividades complementares às do cerimonial, como exposto no Quadro 1.

Quadro 1: Outras atividades também exercidas pelo Cerimonial.

\begin{tabular}{|ll|}
\hline Universidade & Atividades \\
\hline UFCA & Realiza aproximadamente 800 atendimentos com os mais diversos serviços. \\
UFPE & Além dos eventos oficiais, são responsáveis por recepções às autoridades nacionais e internacionais, pela \\
UNILAB & organização das viagens do Reitor e do Vice-Reitor e demais servidores de interesse do Gabinete do Reitor.
\end{tabular}


(1) acompanhamento do Reitor em eventos externos à Universidade;

(2) visitas oficiais externas em acompanhamento ao Reitor;

(3) viagens institucionais aos Campi da UFC no interior do Estado;

(4) reuniões com comissões de formatura;

UFC (5) reuniões para orientações de eventos nas unidades acadêmicas da UFC;

(6) consultoria institucional às Unidades Acadêmicas para a realização de eventos que não são organizados pelo Cerimonial;

(7) avaliação posterior do grau de satisfação na realização dos eventos;

$\begin{array}{ll}\text { UNIVASF } & \text { (8) assinaturas de convênios, eventos est } \\ \text { Uesponsável pelas passagens e diárias. }\end{array}$

De todo modo, as atividades complementares apresentadas no Quadro 1 não implicam dizer que são tarefas exclusivas da equipe de cerimonial da Universidades que apresentaram as referidas informações, mas exemplificam a multiplicidade de atribuições que cada instituição pode atribuir à equipe responsável pelas solenidades universitárias. Notamos que atividades burocráticas, consultoria e organização de viagens se destacam nesse acréscimo de atribuições da equipe de cerimonial, o que, de toda forma, se encontra entre as responsabilidades especificadas por Freiberger et al. (2012).

No mais, podemos destacar a existência de características específicas, conforme diferenças culturais e regionais quanto às questões protocolares e cerimoniais de determinado local, o que está de acordo com Lara (2017), considerando, inclusive, que cada Universidade, além da obediência ao decreto no 70.274/1972, pode incorporar suas próprias regras de cerimonial.

Feitas essas considerações, analisamos quantitativamente os eventos organizados pelo cerimonial para observar se, com base nas informações fornecidas por dezessete universidades federais do Nordeste vinculadas à Andifes, um grande número de eventos decorre de um número de pessoal do cerimonial universitário maior e vice-versa.

Tabela 3: Estatística descritiva do quantitativo da equipe de cerimonial nas Universidades Federais do Nordeste vinculadas à Andifes.

\begin{tabular}{lllll} 
& N & Média & Erro Desvio & Erro padrão da média \\
\hline EQUIPE CERIMONIAL & 15 & 3,00 & 2,104 &, 543 \\
\hline
\end{tabular}

Inicialmente, destacamos que, das dezoito Universidades Federais do Nordeste vinculadas à Andifes, uma universidade não prestou informações sobre seu cerimonial. Ademais, a UFCG informou não possuir cerimonial institucional e a UFOB comunicou que, no período entre 2015 a 2019, não possuía cerimonial institucionalizado. Desse modo, a amostra é aqui estudada é $n=15$, conforme os dados descritivos da Tabela 3. Com isso, considerando o $n$ ser menor que 30, foi utilizada a análise bivariada não paramétrica de correlação por meio do recurso de Kendall.

Tabela 4: Testes de Normalidade. Shapiro-Wilk

Antes de se proceder à correlação, foi realizado o teste de normalidade Shapiro-Wilk, que é o mais indicado para amostras reduzidas. Assim, como se observa na Tabela 4, o nível de significância foi menor que 0,05 (MEYERS, 2013), justificando a realização de teste não paramétrico.

Também foi avaliada a intensidade de correlação conforme o coeficiente de Kendall, haja vista o 
tamanho pequeno da amostra.

Quadro 2: Avaliação qualitativa do grau de correlação entre duas variáveis.

\begin{tabular}{|l|l|}
\hline Coeficiente de correlação & Intensidade da correlação \\
\hline 0,000 & Nula ou inexistente \\
\hline 0,001 a 0,299 & Fraca \\
\hline 0,300 a 0,599 & Regular ou moderada \\
\hline 0,600 a 0,899 & Forte \\
\hline 0,900 a 0,999 & Muito forte \\
\hline 1,000 & Plena ou perfeita \\
\hline
\end{tabular}

Fonte: Diaz et al. (2020).

Ao correlacionar a quantidade da equipe de cerimonial com a quantidade das atividades solenes nas universidades, foi utilizado a intensidade de correlação disposta no Quadro 2, conforme o coeficiente identificado.

Tabela 5: Correlações entre quantidade da equipe de cerimonial e eventos nos anos de 2015 e 2019 nas Universidades Federais do Nordeste vinculadas à Andifes.

\begin{tabular}{|c|c|c|c|c|c|c|c|c|}
\hline & & & $\begin{array}{l}\text { EQUIPE } \\
\text { CERIMONIAL }\end{array}$ & $\begin{array}{l}\text { EVENTOS } \\
2015\end{array}$ & $\begin{array}{l}\text { EVENTOS } \\
2016\end{array}$ & $\begin{array}{l}\text { EVENTOS } \\
2017\end{array}$ & $\begin{array}{l}\text { EVENTOS } \\
2018\end{array}$ & $\begin{array}{l}\text { EVENTOS } \\
2019\end{array}$ \\
\hline \multirow{4}{*}{$\begin{array}{l}\text { tau_b } \\
\text { Kendall }\end{array}$} & deEQUIPE & Coeficiente & de1,000 & ,467 & ,309 & ,197 & ,240 &, 548 \\
\hline & CERIMONIAL & Correlação & & & & & & \\
\hline & & Sig. (2 extrer & les). & ,034 & ,144 & ,334 & ,241 & ,007 \\
\hline & & $\mathrm{N}$ & 15 & 13 & 14 & 15 & 15 & 15 \\
\hline
\end{tabular}

Desse modo, a correlação de tau_b de Kendall mostrou que há correlação positiva e moderada entre a quantidade de pessoas da equipe de cerimonial e a quantidade de eventos oficiais nos anos de 2015 e de 2019: ( $\tau=0,517$; e $\tau=0,641$, respectivamente; para ambos, $p<0,05)$. Quanto à correlação com os eventos em 2016, 2017 e 2018, os dados coletados não apresentaram significância, visto que p >0,05.

Tal resultado se justifica pelo fato que os eventos solenes exigem o cumprimento de normas específicas e uma atenção especial pelo chefe de cerimonial, conforme ensinos de Yanes (2014) e de Malerba (2010), visto suas relevantes atribuições à adequada execução das solenidades. Nesse sentido, a quantidade de atribuições de um cerimonial universitário, conforme especificado por Takashi (2020), demanda das instituições um quantitativo adequado de pessoas para lidar com o cumprimento das normas especificadas.

Destacamos, dessa forma, que quanto maior a Universidade, certamente aumentará o quantitativo de eventos solenes, como colação de grau, inaugurações, aula magna, etc. Portanto, de modo a atender o acréscimo de cerimônias oficiais, é de se esperar que as Universidades adotem alguns caminhos para organização das solenidades, aumentando sua equipe de cerimonial ou seguindo caminhos alternativos, como terceirização e apoio de estagiários e bolsistas. Isso corrobora como o explicado por Ivo, Marin e Souza (2014) quanto à designação de comissões para colaborar com o cerimonial.

\section{O cerimonial universitário na Universidade Federal de Alagoas}

O cerimonial institucional da UFAL atualmente é composto por três servidoras, sendo o responsável por organizar os eventos institucionais, prezando pelo cumprimento dos protocolos estipulados pelo Decreto 70.274/1972, pelo atendimento adequado das demandas de eventos na Universidade e pela padronização 
na condução das cerimônias oficiais. Conforme informações disponibilizadas no site da universidade em comento ${ }^{2}$, o serviço pode ser requerido por servidores e estudantes, com prazo de atendimento de 05 (cinco) dias úteis. Também é anunciado que a recepção dos interessados é realizada de segunda à sexta-feira, das $9 \mathrm{~h}$ às $18 \mathrm{~h}$, na secretaria do Gabinete da Reitoria, com abertura de processo administrativo pelo menos uma semana antes do evento.

Desse modo, constatamos que o cerimonial institucional da UFAL, além de cuidar das solenidades de praxe da instituição, como colação de grau, inaugurações, posses, etc., também se põe à disposição da comunidade acadêmica para orientar e acompanhar diversos eventos planejados no âmbito da instituição.

Tabela 6: Solenidades da UFAL nos anos 2015 até 2019.

\begin{tabular}{|c|c|c|c|c|c|}
\hline Solenidades & 2015 & 2016 & 2017 & 2018 & 2019 \\
\hline Colação de grau & 27 & 31 & 46 & 64 & 35 \\
\hline Aula inaugural & 5 & 1 & 4 & 3 & 3 \\
\hline Inauguração & 15 & 18 & 1 & 8 & 12 \\
\hline Bienal do Livro & 1 & 0 & 1 & 0 & 1 \\
\hline Calourada & 8 & 3 & 3 & 6 & 2 \\
\hline Semana de Biologia & 1 & 1 & 1 & 1 & 1 \\
\hline Aposição de foto & 1 & 0 & 0 & 0 & 0 \\
\hline Seminário & 1 & 0 & 25 & 2 & 5 \\
\hline Encontro & 2 & 1 & 5 & 0 & 1 \\
\hline Abertura Programa PIBIC & 3 & 1 & 2 & 0 & 1 \\
\hline Congresso & 1 & 0 & 1 & 0 & 1 \\
\hline Comemoração & 1 & 2 & 2 & 0 & 0 \\
\hline Transmissão de cargo Reitor & 0 & 1 & 0 & 0 & 0 \\
\hline Pedra fundamental - doação terreno & 0 & 2 & 0 & 0 & 0 \\
\hline Instalação - museu & 0 & 1 & 0 & 0 & 0 \\
\hline Posse & 0 & 2 & 2 & 2 & 0 \\
\hline Fórum & 0 & 1 & 1 & 0 & 4 \\
\hline Inserção novos servidores & 0 & 1 & 1 & 1 & 1 \\
\hline Homenagens & 0 & 1 & 1 & 2 & 0 \\
\hline Workshop de economia & 0 & 1 & 0 & 1 & 0 \\
\hline Simpósio & 0 & 0 & 1 & 4 & 1 \\
\hline Entrega certificado - excelência acadêmica & 0 & 0 & 1 & 1 & 1 \\
\hline Mesa redonda & 0 & 0 & 2 & 0 & 0 \\
\hline Oficina regional da educação & 0 & 0 & 1 & 0 & 0 \\
\hline Premiação olimpíada matemática & 0 & 0 & 1 & 1 & 0 \\
\hline Audiência pública & 0 & 0 & 1 & 2 & 2 \\
\hline Reunião da SBPC & 0 & 0 & 0 & 1 & 0 \\
\hline Jornada acadêmica & 0 & 0 & 0 & 1 & 0 \\
\hline Projeto Future-se & 0 & 0 & 0 & 0 & 2 \\
\hline Debate & 0 & 0 & 0 & 0 & 1 \\
\hline Colóquio & 0 & 0 & 0 & 0 & 1 \\
\hline Assinatura de contrato & 0 & 0 & 0 & 0 & 1 \\
\hline TOTAL & 66 & 68 & 103 & 100 & 76 \\
\hline
\end{tabular}

Através de resposta ao pedido de informação (número de protocolo: 23546.041415/2020-23; chave de acesso: rtsd7190), a UFAL forneceu os dados dispostos na Tabela 6, contendo a especificação das solenidades acompanhadas por sua equipe de cerimonial entre 2015 e 2019. Nela, é possível perceber cinco eventos mais repetitivos, a saber: colação de grau, aula inaugural, inauguração, calourada e seminário.

Assim, as servidoras responsáveis pelo cerimonial da UFAL acabam por se ocupar mais nas atividades promovidas pela própria instituição, que se reiteram constantemente, conforme já mostrado acima. Com isso, conseguimos observar que elas fazem uso constante do seu tempo para prestar orientações e

\footnotetext{
${ }^{2}$ https://servicos.ufal.br/orgaos/gabinete-da-reitoria/cerimonial-institucional
} 
consultoria sobre as solenidades de interesse da comunidade acadêmica, especialmente aquelas que constantemente se repetem, como colação de grau e seminário. Por isso, uma padronização indicada por um manual com orientações das solenidades de ocorrência constante seria de bom alvitre para a celeridade e efetividade do trabalho das cerimonialistas.

Ademais, observamos também a ausência de normativos internos que disciplinem as atribuições do cerimonial da UFAL e que listem as solenidades e cerimônias consideradas oficiais na UFAL, importantes para orientação e indicação de procedimentos. Logo, a expertise do cumprimento protocolar cerimonial fica a cargo exclusivo das três servidoras que compõem a equipe, que são experientes na atividade que desenvolvem. Ressalte-se que "apenas essas servidoras compõe o Cerimonial Institucional e que são responsáveis pela organização dos eventos da Universidade" (UFAL, 2017).

Especificamente quanto à colação de grau, vemos que a instrução trazida pela Universidade é no sentido que, "agendada a solenidade, a Comissão de Formatura deverá se reunir com a Comissão de Cerimonial e Eventos para dar ciência do evento, agendar os ensaios para cerimônia e receber demais instruções" (UFAL, 2020). Portanto, os esclarecimentos são comumente repassados verbalmente, seja pessoalmente ou por telefone, aos alunos interessados e servidores interessado.

Quadro 2: Composição da Equipe de Cerimonial da UFAL

\begin{tabular}{|l|l|l|l|}
\hline Servidoras & Lotação & Função & Ingresso no Órgão \\
\hline Servidora 1 & Gabinete da Reitoria & Assistente em Administração & $02 / 01 / 1981$ \\
\hline Servidora 2 & Pró-Reitoria Estudantil & Técnico em Assuntos Educacionais & $18 / 06 / 1974$ \\
\hline Servidora 3 & Faculdade de Direito de Alagoas & Assistente Social & $13 / 05 / 1974$ \\
\hline
\end{tabular}

Fonte: Dados extraídos de UFAL (2017).

Quanto às funções descritas no Quadro 2, inferimos que as servidoras do cerimonial da UFAL possuem formações distintas, o que encontra consonância com o pesquisado por Carvalho et al. (2018). Outro fato que chama atenção é que, além de o conhecimento técnico estar concentrado na capacidade das servidoras em comento e de não ter sido encontradas instruções escritas sobre detalhes relevantes das solenidades da instituição, toda composição da equipe de cerimonial está às vésperas de uma iminente aposentadoria. Conforme Quadro 2, as cerimonialistas possuem cerca de quatro décadas de atividades no serviço público, existindo possibilidade de as três se afastarem da função concomitantemente.

Isso destaca a relevância de se construir alternativas para, além de não sobrecarregar o cerimonial institucional, democratizar o conhecimento e possibilitar uma pacífica transição para futuros servidores que venham compor a equipe de cerimonialistas da universidade no momento onde houver necessidade. Ocorre que, ainda que se decida por uma futura terceirização ou apoio de uma nova equipe, com servidores, estagiários e bolsistas, tal transição não é imediata; no primeiro caso, demandaria de um processo licitatório; no último caso, um devido treinamento de capacitação.

Outra possível melhoria, se encontra no método para contatar o cerimonial institucional. O e-mail indicado pela UFAL em seu site ${ }^{3}$ não é específico do cerimonial, mas é o pertencente ao gabinete reitoral ${ }^{4}$

\footnotetext{
${ }^{3}$ https://servicos.ufal.br/orgaos/gabinete-da-reitoria/cerimonial-institucional

${ }^{4}$ gr@reitoria.ufal.br
} 
que recebe todo o tipo de demanda da Universidade. Da mesma forma quanto ao número de telefone e ao local físico para realização de atendimento.

Desse modo, ocorre uma mistura entre os diversos serviços exercidos no gabinete da reitoria e o serviço específico de cerimonial institucional da UFAL, visto que esse último não se encontra estruturado na Universidade. Com isso, as servidoras apontadas no Quadro 2, em muitas oportunidades, têm que se deslocar ao Gabinete da Reitoria e, concomitantemente às atividades inerentes à secretaria daquele setor, elas realizam atendimentos, organizam roteiro, guardam os materiais dos eventos.

Logo, verificamos a necessidade de se criar um ambiente que gere uma motivação à equipe e de se manter um quadro profissional qualificado para benefício da própria universidade com resultados positivos pela atuação de um cerimonial habilidoso na condução das solenidades, o que encontra concordância com o posicionamento de Colombo et al. (2011). Assim, observadas essas questões, ainda é mister analisar se apenas três pessoas na composição da equipe de cerimonial de uma universidade federal é um quantitativo comum em outras instituições de ensino superior.

Tabela 7: Teste da uma amostra do quantitativo da equipe de cerimonial da UFAL em comparação às Universidades Federais do Nordeste vinculadas à Andifes. Valor de Teste $=3$

\begin{tabular}{llllll} 
& $\mathrm{t}$ & df Sig. (2 extremidades) & Diferença média & $\begin{array}{l}95 \% \text { Intervalo de Confiança da Diferença } \\
\text { Inferior }\end{array}$ & Superior \\
\hline EQUIPE CERIMONIAL &,- 000 & 141,000 &,- 000 & $-1,17$ & 1,17 \\
\hline
\end{tabular}

Observando a Tabela 7, temos que o teste-t para a amostra analisada mostrou que a média da quantidade de pessoas que compõe a equipe de cerimonial nas universidades federais do Nordeste associadas à Andifes não é diferente da quantidade existente na UFAL (t(14) = -0,000, p > 0,05), dado que também é confirmado pela Tabela 3, que expõe a média de componentes do cerimonial em 3,00.

A seguir, observamos a média de eventos oficiais sob responsabilidade do cerimonial institucional da UFAL em comparação às demais Universidades Federais do Nordeste vinculadas à Andifes.

Tabela 8: Teste da uma amostra do quantitativo de eventos da UFAL em comparação às Universidades Federais do Nordeste vinculadas à Andifes. Valor de Teste $=66,68,102,100$ e 76, respectivamente

\begin{tabular}{|c|c|c|c|c|c|c|}
\hline & \multirow[b]{2}{*}{$\mathrm{t}$} & \multirow[b]{2}{*}{ df } & \multirow[b]{2}{*}{ Sig. (2 extremidades) } & \multirow[b]{2}{*}{ Diferença média } & \multicolumn{2}{|c|}{ 95\% Intervalo de Confiança da Diferença } \\
\hline & & & & & Inferior & Superior \\
\hline EVENTOS 2015 & 157 & 12 & ,878 & 2,154 & $-27,68$ & 31,99 \\
\hline EVENTOS 2016 &,- 846 & 13 & ,413 & $-10,571$ & $-37,55$ & 16,41 \\
\hline EVENTOS 2017 & $-3,434$ & 14 &, 004 & $-44,467$ & $-72,24$ & $-16,69$ \\
\hline EVENTOS 2018 & $-3,142$ & 14 & ,007 & $-39,200$ & $-65,96$ & $-12,44$ \\
\hline EVENTOS 2019 & $-1,270$ & 14 & ,225 & $-18,933$ & $-50,90$ & 13,04 \\
\hline
\end{tabular}

Observando a Tabela 8, podemos perceber que os eventos oficiais da UFAL nos anos de 2015, 2016 e 2019 ficaram na mesma média das demais universidades aqui pesquisadas $(p>0,05)$. Não obstante, a UFAL superou o quantitativo de eventos em relação às demais instituições nos anos de 2017 e 2018 (p < 0,05), que corrobora com o apresentado na Tabela 6, haja vista o aumento de colação de grau, seminários e simpósios. Salientamos que utilizamos cinco valores de testes diferentes, a saber: 66, 68, 102, 100 e 76, referentes à quantidade de eventos oficiais na UFAL nos anos 2015, 2016, 2017, 2018 e 2019, respectivamente. 
Com isso, ainda que em alguns momentos o total de eventos possa aumentar em relação ao ano anterior, o número de solenidades da UFAL e a quantidade de pessoas que compõe seu cerimonial institucional é proporcional às demais Instituições do Nordeste pesquisadas. Como visto, a equipe possui experiência, considerando que conta com servidoras com cerca de quarenta anos de serviço público e mais de vinte e três anos no cerimonial institucionalizado, decorrente da portaria no 69/1997-GR.

Não obstante, a ausência de estruturação do cerimonial universitário da UFAL é um fator limitante à melhoria da efetividade da equipe, visto que as servidoras concorrem com as atribuições dos setores onde estão lotadas, além de não haver espaço individualizado, meios para contato exclusivos, veículo próprio e manual de procedimento específico de cerimonial institucional. Essas circunstâncias são fatores contingenciais que influenciam o desenho organizacional, conforme corrobora Chiavenato (2008).

\section{CONCLUSÕES}

Pelo presente estudo, podemos tecer considerações sobre como dezessete universidades públicas federais do Nordeste dimensionam o quantitativo da equipe de cerimonial em relação à demanda de eventos oficiais que promovem. Para tanto, observando o exemplo da Universidade Federal de Alagoas, foi possível identificar as principais dificuldades enfrentadas pela Instituição e apresentar possibilidades de melhoria.

Considerando o exemplo das universidades federais do nordeste pesquisadas, todas elas associadas à Andifes, percebemos que a institucionalização do cerimonial universitário não é unânime. A UFCG não institucionalizou seu cerimonial e a UNILAB, a UFOB e a UNIVASF têm a equipe institucionalizada há menos de cinco anos. E, quanto à UFSB, houve desativação em dezembro de 2018. Isso demonstrou o uso de autonomia pelas universidades quanto ao arranjo de sua estrutura organizacional.

Podemos notar também que diversas atividades burocráticas próprias dos cargos ocupados pelos servidores somam-se às atribuições do cerimonial, o que acrescenta tarefas aos componentes da equipe, tais como consultoria e organização de viagens, tudo conforme as especificidades locais de cada instituição. Essa realidade não difere na UFAL, visto que as cerimonialistas, conforme Quadro 2, ocupam diversos cargos, estão lotadas em setores diferentes, além do fato de organizarem as atividades antecipatórias do cerimonial na secretaria do gabinete reitoral, ou seja, em espaço não individualizado.

Não obstante, levando em conta a amostra de 15 universidades federais do Nordeste, conforme Tabela 3, notamos que é comum às instituições envidarem esforços na composição de seu cerimonial quando há um número significativo de solenidades a serem acompanhadas. Isso foi provado pela existência de correlações positivas moderadas entre o quantitativo de eventos e a quantidade de pessoas na equipe de cerimonial durante os anos 2015 e 2019, respectivamente.

No caso da UFAL, pelos dados dispostos na Tabela 6 e em atendimento ao primeiro objetivo específico da presente pesquisa, constatamos os eventos solenes realizados, identificando, inclusive, as cinco solenidades mais repetitivas, a saber: colação de grau, aula inaugural, inauguração, calourada e seminário. Ademais, seguindo nosso segundo objetivo específico, notamos a ausência de resolução que discipline as atribuições do cerimonial da UFAL, de portaria que liste as solenidades e cerimônias consideradas oficiais na 
universidade e de um manual de normas e procedimentos de cerimonial.

Por isso, dando sequência ao terceiro objetivo específico, concluímos ser viável a construção e divulgação de instruções aos interessados, visando a manutenção da adequada consecução dos eventos institucionais, bem como o melhor uso do tempo pela equipe de cerimonial. Para tanto, a elaboração de um Manual de Eventos e Cerimonial da UFAL, de modo a contemplar todas as etapas de planejamento de um evento e especificar os procedimentos da elaboração de Cerimônias, detalhando os eventos importantes e recorrentes na universidade, é instrumento oportuno para efetividade do cerimonial institucional, seja na federal de Alagoas ou quaisquer universidades em situação análoga.

Ademais, com todos os dados obtidos, vimos que uma Universidade deve manter uma estrutura organizada de seu cerimonial para que haja adequado cumprimento das normas protocolares. Desse modo, a composição da equipe dever ser observada pela instituição, seja quanto ao perfil de seus componentes, em consonância com apontado pelo referencial teórico, bem como quanto à possibilidade de manter a continuidade dos serviços.

Na presente pesquisa, também percebemos que o número de três pessoas para a composição de uma equipe de cerimonial institucional é uma quantidade padrão nas universidades federais do Nordeste pesquisadas, conforme Tabelas 3 e 5; e que o montante de solenidades nessas instituições equipara-se às existentes na UFAL. Ademais, notamos pelo Quadro 2 que seu cerimonial conta com servidoras com vasta experiência profissional, mas na iminência de deixarem o cargo, considerando o tempo de serviço.

Com isso, compreendemos que, além de produzir instruções escritas, a instituição pode fazer uso de um modelo de gestão por competências, observados os limites de reposicionamento permitidos no setor público ou, até mesmo, se for o caso, repensar o desenho organizacional, de modo que possibilite a não paralização do cerimonial institucional. Ademais, a pesquisa concluiu ser pertinente a estruturação do cerimonial universitário em espaço individualizado para melhor execução das atividades específicas.

Como sugestão de pesquisa futura, temos a possibilidade de analisar o estresse e qualidade de vida dos cerimonialistas, visto que este estudo não abordou sobre possíveis desgastes e desmotivações pelas atribuições do cerimonial em relação aos diversos eventos institucionais. Dos aspectos limitantes da pesquisa, salientamos que, considerando a observação participante de um dos pesquisadores, pode haver uma visão parcial do objeto estudado. Por fim, esperamos com este trabalho contribuir com a valorização do cerimonial público, mormente o institucional das universidades.

\section{REFERÊNCIAS}

BETTEGA, M. L.. Cerimonial universitário: três modalidades de colações de grau. Caxias do Sul: UCS, 2005.

BRASIL. Decreto n. 70.274, de 9 de março de 1972 e suas alterações. Normas do cerimonial público da República Federativa do Brasil e ordem geral de precedência. Brasília: DOU, 1972.

BRASIL. Ministério da Educação. Guia de eventos, cerimonial e protocolo da rede federal de educação profissional e tecnológica. Brasília: MEC, 2010.
BORGES, A. G.. Cerimonial e protocolo: correlações e aplicação no turismo. Multitemas, n.27, p.71-86, 2002. DOI: https://doi.org/10.20435/multi.v0i27.806

BORGES, C.; SÁ, A.. Manual de Direito administrativo facilitado. 2 ed. Salvador: Juspodivm, 2018.

CARVALHO, R. O.; SANTOS, A. C.; PINHO, F. P.. Secretariado e cerimonial: possibilidades de atuação e empregabilidade.

Revista do Secretariado Executivo, Passo Fundo, v.13, 
p.109-122, 2018. DOI:

https://doi.org/10.5335/ser.v13i0.8097

CESAR, A.. Aprender para fazer \& fazer aprendendo: planejamento, organização e execução de cerimonial de eventos. 2016.

CHIAVENATO, I.. Administração geral e pública. 2 ed. Rio de Janeiro: Elsevier, 2008.

CHIAVENATO, I.. Gestão de pessoas: o novo papel dos recursos humanos nas organizações. 3 ed. Rio de Janeiro: Elsevier, 2010.

COLOMBO, S. S.; RODRIGUES, G. M.. Desafios da gestão universitária contemporânea. Porto Alegre: Artmed, 2011.

DIAZ, J. O.; WERKA, H. M. G.; CAPP, E.; NIENOV, O. H.. 9 Correlações, risco, razão de chances e avaliação de testes diagnósticos. In: CAPP, E.; NIENOV, O. H.. Ginecologia e obstetrícia bioestatística quantitativa aplicada. Porto Alegre: UFRGS, 2020.

DORTA, L. O.. Fundamentos em técnicas de eventos. Porto Alegre: Bookman, 2015.

FIELD, A.. Discovering Statistics Using IBM SPSS Statistics. 5 ed. Sage, 2017.

FREIBERGER, Z.; OLIVEIRA, M.. Cerimonial, Protocolo e Eventos. Curitiba: Instituto Federal de Educação, Ciência e Tecnologia do Paraná, 2012.

GIL, A. C.. Métodos e técnicas de pesquisa social. 6 ed. São Paulo: Atlas, 2008

HASCKEL, A. L.; RIFFEL, C. M.. A prática do cerimonial público nas prefeituras dos cinco maiores municípios de Santa Catarina. In: V ABRAPCORP, 5. Anais. 2011.

IVO, A. A.; MARIN, E. C.; SOUZA, L. M.. Gestão de Eventos: Orientações Básicas para o Contexto das Universidades. Kinesis (Santa Maria), v. 32, p. 100-116, 2014. DOI: https://doi.org/10.5902/2316546416508

LARA, L. M. M.. Cerimonial e protocolo. Ponta Grossa: UEPG, 2017.

LAKATOS, E. M.; MARCONI, M. A.. Fundamentos de metodologia científica. 8 ed. São Paulo: Atlas, 2017.
MALERBA, R.. Técnicas de cerimonial e protocolo. São Paulo: IFSP, 2010.

MEYERS, L. S.. Performing data analysis using IBM SPSS. Hoboken: Wiley, 2013.

NAANKIEL, P. W.; OVIEMUNO, E. W.; CHOLLOM, C. J.; SANI, A. S.. The concept and principle of precedence in diplomatic practice. The Pillar, Journal of Arts and Social Sciences, Bokkos-Nigeria, v.1, n.1, p.54-62, 2013.

PINHEIRO, C. M. S.. Curso de cerimonial e regras de protocolos. Curitiba: IESDE, 2012.

PRANDO, L.. Projeto de pesquisa de marketing. São Paulo: Senac, 2018.

ROQUE, M. A.; MEDEIROS, L. M. V.. A atuação do secretário executivo na gestão de eventos. Revista do Secretariado Executivo, Passo Fundo, v.12, p.17-29, 2017. Dol: https://doi.org/10.5335/ser.v12i0.6429

SILVA, E. L.; MENEZES, E. M.. Metodologia da pesquisa e elaboração de dissertação. 4 ed. Florianópolis: UFSC, 2005.

SILVA, J. S. S.. Cerimonial e protocolo na defesa de monografia dos cursos de graduação: um rito de passagem. Revista Turismo \& Sociedade, Curitiba, v.1, n.1, p.43-52, 2008. DOI: http://dx.doi.org/10.5380/tes.v1i1.11924

SILVA, R. A. S. A. E.. O discurso do mestre de cerimônias: perspectiva dialógica. Dissertação (Mestrado em Linguística Aplicada e Estudos da Linguagem) - Pontifícia Universidade Católica de São Paulo, São Paulo, 2007.

TAKASHI, C.. Os 3 B's do Cerimonial: Introdução às Normas do Cerimonial Público Brasileiro. 2020.

UFAL. Universidade Federal de Alagoas. Cerimonial Institucional. Maceió: Universidade Federal de Alagoas, 2020 .

UFAL. Universidade Federal de Alagoas. Justificativa para inscrição de servidores no X Encontro Nacional de Cerimonial Universitário. Maceió: Universidade Federal de Alagoas, 2017.

YANES, A. F.. Cerimonial, protocolo e etiqueta em eventos. São Paulo: Saraiva, 2014.

ZANELLA, L. C. H.. Metodologia de estudo e de pesquisa em administração. Florianópolis: UFSC, 2009.

A CBPC - Companhia Brasileira de Produção Científica (CNPJ: 11.221.422/0001-03) detém os direitos materiais desta publicação. Os direitos referem-se à publicação do trabalho em qualquer parte do mundo incluindo os direitos às renovaç̃es, expansões e disseminações da contribuição, bem como outros direitos subsidiários. Todos os trabalhos publicados eletronicamente poderão posteriormente ser publicados em coletâneas impressas sob coordenação da Sustenere Publishing, da Companhia Brasileira de Produção Científica e seus parceiros autorizados. Os (as) autores (as) preservam os direitos autorais, mas não têm permissão para a publicação da contribuição em outro meio, impresso ou digital, em português ou em tradução. 